\title{
Research on Counselor Team Management Based on Two- factor Theory
}

\author{
Zheng Yan ${ }^{1, a}$ and Bai You-jun ${ }^{2, b}$ \\ ${ }^{1}$ International Institute of Education, Hainan College of Economics and Business, Haikou, 571127, \\ China \\ ${ }^{2}$ College of Engineering and Technology, Hainan College of Economics and Business, Haikou, \\ 571127, China \\ amumuchen1985@163.com, b642baiyoujun@163.com
}

Keywords: Hygiene factors, Incentive factors, Counselor, Team management.

\begin{abstract}
This article takes the construction and management of college counselors as the research object, uses Herzberg's two-factor theory to analyze and research the construction and development status of counselors from the perspective of management, and through the existing problems and influencing factors. Analyze and propose relevant improvement measures to provide the leadership of the university with constructive opinions and suggestions for reference.
\end{abstract}

\section{Elaboration on hygiene factors and incentive factors in the construction and management of Counselors}

In the late 1950s, Frederick Hertzberg, the American behavioral science manager in the United States, proposed a two-factor theory based on his and his assistants' surveys and interviews with 203 engineers and accountants in the Pittsburgh area.The two-factor theory states that there are two main factors that motivate people to work: one is the hygiene factor and the other is the incentive factor.Employees are satisfied with the factors of work itself or job content, which are called incentive factors. The reason of Employees who are dissatisfied is always because of the working environment or work relationship, which is called hygiene factor. In the construction and management of the counselor team, the hygiene factors include the various policy measures,institutional guarantee,colleague relationship, salary and welfare, working environment and conditions. When these conditions deteriorate, counselors will be dissatisfied. When these factors increase, counselors will eliminate dissatisfaction, but these fators will not inspire them. The incentive factors include the degree of acceptance inside and outside of the colleage of the counselors, the pleasure of the work, the sense of achievement of the students, the challenging work, the appreciation and recognition of the leaders, the value of self realization, the opportunities for growth and development.Under the premise that the incentive factors do not let the counselors feel "unsatisfactory", the promotion of these incentives will play an effective and lasting incentive for the enthusiasm of the counselors.

\section{Analysis on the current situation of hygiene factors and incentive factors in the construction and development of counselor team}

\subsection{High work intensity and low pay}

Although the Ministry of education provides that full-time counselors in Colleges and universities should be equipped with at a ratio of least 1:200 students, the actual situation is that many colleges and universities are not equipped with the standard.In addition to bringing students, many counselors also serve as general secretary of the Communist Youth League, secretary of the Party branch of the Communist Party of China, and secretary in charge of students'employs, undertaking many other missions.Many teachers and even administrative cadres in colleges and universities have a common concept: As long as the work are relevant to students, they should all be done by the counselors.Most 
colleges and universities require counselors to be on duty 24 hours a day, which means that in addition to the normal work to deal with a large number of daily affairs and all kinds of student emergencies, the normal rest time may change to overtime at any time.Compared with the high-intensity workload, the average salary level of the counselor team is generally lower than that of the teachers of the same period.Moreover, ordinary teachers who work outside of class will have corresponding performance pay or rewards, while non-worker overtime hours are normal for connselors and they generally do not receive overtime pay.In the long run, this kind of basic hygiene factor does not let the counselor feel "no dissatisfaction", and will create a general mood of neglect in the counsellor's team.

\subsection{High work pressure and lack of security system}

Through interviews and investigations with college counselors in Hainan, it is concluded that the pressure of counselors' work is high, and the main reason is "fear of students' accidents".In recent years, college students' mental health problems are becoming more and more unoptimistic. According to the survey, up to $1 / 3$ of the students in colleges now have psychological problems of big or small.Taking a certain college in a higher vocational college in Hainan as an example, there are about 200 freshmen. Through the psychological tests for freshman and counselors' investigation, there are more than 40 students with serious psychological problems, the proportion of which is more than $20 \%$.In many colleges and universities, especially in higher vocational colleges, the barriers to entry are reduced, and the quality of students declines. Under the influence of the large environment, the students' minds are diversified and individualized. As a result, the education and management work of the counselors becomes more difficult. They have to devote a great deal of time and energy to solving the problems of the students, such as: overindulging in games, eating and drinking, night out and dormitory contradictions.In particular, it is necessary to handle some students'emergencies at any time, leading to a high degree of ideological and spiritual tension.However, as long as something bad happened to the students, or the students get themselves some big trouble, the good counselor is generally difficult to get a promotion or an opportunity for evaluation for a considerable period of time, because the counselor is the first security responsibility of the students.Counselor work is known as "high-risk occupation". Once encountering student emergencies, the counselor is usually the first person to face the conflict between parents and colleges. Tired of maintaining the students'safety everyday, it is difficult for the counselor to have more energy and enthusiasm to devote to the theoretical study and practical research of ideological and political education.In addition, colleges usually pay more attention to students' mental health, but they generally neglect the counseling and protection mechanisms for counselors who are always in the high-intensity and high-stress situations.Counselors are always "trash cans" dumped by all kinds of negative emotions of students, but the "junk" that has accumulated on themselves for a long time has no place to dump.

\subsection{Small promotion space and poor development path}

Though the state has introduced relevant policies to clearly define the counselor's dual status, which can both be assessed in the teacher's professional title, and can also participate in the promotion of management positions, but in fact, most colleges and universities do not agree with the policies or have more restrictions for the counselors. The counselors use work time and even part of the rest time in the daily management of students, activities and ideological and political education. Their own limitations make them at a disadvantage in competition with full-time teachers.And the administrative posts in Colleges and universities are very limited, some colleges and universities still have the phenomenon of overstaffed,Counsellors' chances of getting promotion in managerial positions are relatively limited.

\subsection{Low occupational prestige and lack of identity}

Occupational prestige refers to the comprehensive evaluation of the meaning, value and reputation of a profession by public opinion. It has the dual attributes of introversion and extroversion. The introverted attribute is the sense of belonging of a counselor to his professional group and his self 
recognition of his career. The external attributes are public opinion and people's yearning for the Counselor's profession, the professional charm and honor that this professional group shows.

"Nanny", "All Kinds of Oil," "Firefighters," and "Miscellaneous Workers" are the "definitions" of counselors in colleges and universities.In fact, the current academic qualifications of college counselors are generally postgraduates, and they are not lower than those of other teachers when they enter school.However, because of the defects of the system and the deviation of understanding, some managers and full-time teachers in Colleges and universities think that the technical nature of the counselor is not strong, and the counselors only dealing with some daily affairs. They do not understand, support or even dismiss the counselor's work. At the student level, most of them also think that counselors are their "life nannies" and do not give the counselor the same respect as other teathers. They believe that counselors should help them solve many life problems. If the counselors have a bad attitude toward them, or if the problems are not resolved, they will also report to the relevant leaders and let the leaders "backing them up".This lower occupational prestige will inevitably lead the counselor to some degree of frustration and self-worth identity, which will affect the enthusiasm of the work.

\section{Improve the hygiene and incentive factors in a two pronged counsellor team building and management incentive mechanism.}

\subsection{Improve the salary and welfare of counselors, and reduce their work intensity reasonably}

According to Hertzberg's two-factor theory, the salary and welfare are the hygiene factors that affect the job satisfaction of counselors.However,hygiene factors and incentive factors can be transformed into each other under certain conditions. It is very necessary to motivate counselors by making use of hygiene factors reasonably.In addition to ensuring that the basic salary of the counselor is not less than the average salary of the ordinary teacher, special post allowance should be set up for the counselor, and the counselors's usual overtime and communication fee should be subsidized.At the same time, qualified colleges and universities should also implement the class-adviser system and appropriately share the workload of the counselor's daily affairs.On the one hand, it is reasonable to reduce the work intensity of the counselors, and on the other hand, the counselors have the time and energy to pay attention to the theoretical study and practical research of ideological and political education.

\subsection{Improve the system of protecting the rights and interests of counselors, and attach importance to their psychological needs}

How to ease the work pressure of the counselor, the counselor's university has a great responsibility.Colleges and universities should provide direct help for counselors to relieve their inner perplexity and psychological pressure, which is also an important hygiene factor to ensure that the counselors are" "not dissatisfied" with the work environment.First of all, we should respect the career of the counselor from the overall level of the school, respect the hard work of the counselor.At the same time, the leadership should let the counselors can feel that regardless of any difficulties, the school is the strong backing of the counselors when dealing with student emergencies and confronting parents and school conflicts. Secondly, for the counselor's most stressful situation of "fear of student accidents",Hiring out-of-school psychologists as long-term consultants,conducting related seminars regularly, training the handling of emergency and relieving psychological pressure of counselors are very important.Third,counselors should improve their psychological quality and their ability to resist stress, strengthen their self-adjustment, and actively look for their own methods of decompression. 


\subsection{Implement the double promotions of counselors' titles and positions to enhance professional identity}

On the one hand, a scientific and effective position promotion mechanism for counselors should be established. In view of the practical factors of limited administrative posts in Colleges and universities, the relevant policies should be proposed. For example, the counselor is required to work for a long period of time and has excellent job evaluation. Although he does not have a position, he can enjoy the corresponding salary for promotion. On the other hand, the professional title assessment agency and assessment requirements can be set independently, and the specific nature of the counselor's occupation can be fully considered.Thirdly, the full-time counselors will be an important source of training and selection of Party and government reserve cadres, and the training of counselors should be strengthened. The above three aspects provide conditions for the promotion and development of counselors, and at the same time, they also increase the professional status and sense of identity of counselors, which are important motivating factors for feasibility.

\section{References}

[1] F. Herzberg, The motivation to work, China Renmin University Perss, pp. 98-113, 2009.

[2] W. J .Juan, Occupational prestige analysis of college counselors, Journal of Wuhan Textile University, vol.26, pp. 70-72, 2013.

[3] G. Z. Hua and G. Y. Zhen, The current situation and Countermeasures of College Counselors' mental health problems, Kao Shi Zhou Kan, vol.07, pp. 204-205, 2011.

[4] G. Z. Yuan, Several ideas on the construction of college counselor team from the perspective of management theory, Shanxi Agricultural Economy, vol. 03, pp. 111-112, 2018.

[5] Y. Lin, Research on the innovative mechanism of university counselor team construction — based on collaborative management perspective, Journal of Liaoning Agricultural Technical College, vol. 06, pp. 55-56, 2017.

[6] Z. Yan, Studies on the troop construction of university instructors from the perspective of management ideas, Heilongjiang Researches on Higher Education, vol. 04, pp. 106-108, 2015.

[7] C. W. Pu, Research on the construction of university counselor team from the perspective of human resource management, Co-Operative Economy \& Science, vol. 04, pp. 96-97, 2017. 